\title{
Production of soil amendment by utilization of the weed Amaranth
}

\author{
Julia Karaeva ${ }^{1, *}$, Svetlana Timofeeva ${ }^{1}$, Anton Mindubaev ${ }^{1}$, and Marat Gilfanov ${ }^{2}$ \\ ${ }^{1}$ Institute of Power Engineering and Advanced Technologies, FRC Kazan Scientific Center, Russian \\ Academy of Sciences, Kazan, 420111, Russia \\ ${ }^{2}$ Kazan National Research Technological University, Kazan, 420015, Russia
}

\begin{abstract}
There is a possibility of using agricultural waste, in particular weeds, in innovative technologies for the restoration of disturbed land in order to increase fertility. Digestate, after anaerobic digestion of manure and weed plant Amaranthus retroflexus L. (AR), as well as solid carbonaceous residue after pyrolysis of AR. The combination of digestate, which contains high concentrations of total nitrogen, phosphorus, potassium, and solid carbonaceous residue, provides a new composite soil amendment. It has high potential as a source of nutrients because it contains a large amount of mineral components. The soil amendment does not contain toxic elements such as: lead, cadmium, mercury, arsenic and nickel, but the zinc and copper content exceeds the recommended values.
\end{abstract}

\section{Introduction}

Anaerobic digestion is one of the most popular technologies for processing agricultural waste. In digestate the total nitrogen is retained, and organic nitrogen compounds from the original raw materials are already converted into ammonium form, well assimilated by plants [1]. It should be noted that it is an analogue of mineral fertilizers in terms of speed of action, as total nitrogen, phosphorus and potassium are in a form easily accessible to plants [2].

At present, another important direction for obtaining high-quality fertilizers is pyrolysis of organic waste to produce carbon-enriched solid carbonaceous residue [3,4]. It is a soil conditioner because its highly porous structure allows keeping optimal conditions for aeration [5]. As a natural sorbent, carbonaceous residue accumulates moisture during irrigation (rains) and then gradually gives it to the root systems of plants [6]. Thus, the application of the solid residue affects soil fertility and stimulates plant growth $[4,7]$.

However, the effectiveness of any fertilizer depends on the type of soil and the type of crops being cultivated. For example, poorly humusified soils are characterized by poor structure and insufficiently favorable water-chemical indicators, also such soils contain insufficient amounts of nutrient mineral components in their composition. One of the ways to solve the above problems for such soils is to apply composite soil amendments containing digestate and hard carbon residue [8].

*Corresponding author: julieenergy@list.ru 
The purpose of the present study was to assess the possibility of producing soil amendment by utilization of weed amaranth. For this purpose, a combined technology combining anaerobic digestion and pyrolysis was used.

\section{Materials and methods}

Subjects: digestate obtained from digestion of cow manure and AR biomass, and solid carbonaceous residue after AR pyrolysis. ARs were collected in the field $\left(55^{\circ} 63^{\prime} \mathrm{N}, 48^{\circ} 73^{\prime}\right.$ E) during the growth phase characterized by seed maturation (Fig. 1).

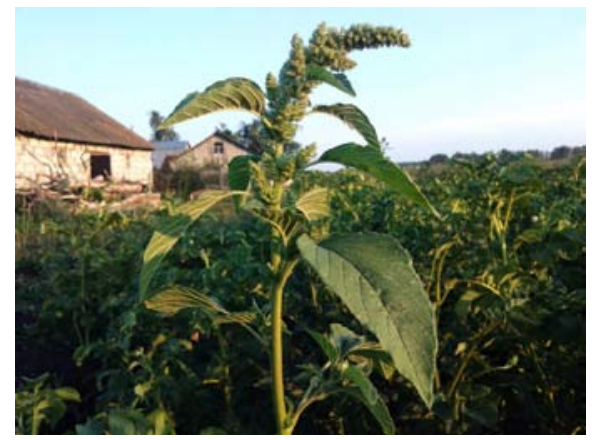

Fig. 1. Photo of Amaranthus retroflexus $L$.

A laboratory biogas plant described in [9] was used to produce digestate. Biogas production was carried out in mesophilic mode at a temperature of $37{ }^{\circ} \mathrm{C}$. Digestate was dried at $105^{\circ} \mathrm{C}$ for 24 hours to air-dry in a drying cabinet ShSL-43/250V (Russia). Then it was subjected to milling in a planetary ball mill Activator-2SL with a selection of particles not more than $3 \mathrm{~mm}$.

Pyrolysis of AR biomass was carried out in a laboratory unit, allowing for thermochemical processing of organic raw materials of any composition. The dried and crushed sample was placed in a tubular reactor, which was purged with nitrogen to maintain an inert environment in the process. The pyrolysis process temperature was $550{ }^{\circ} \mathrm{C}$, with a heating rate of $10^{\circ} \mathrm{C} / \mathrm{min}$. After the experiment was completed, the reactor was cooled and the products obtained were analyzed.

Elemental composition of digestate and solid carbonaceous residue was determined on a CHNS analyzer EuroEA3000 made by "Eurovector SpA" (Italy). Chemical analysis of the mineral part was studied using an energy dispersive fluorescence X-ray spectrometer EDX$800 \mathrm{HS} 2$ produced by "Shimadzu" (Japan) by a semi-quantitative method.

\section{Results}

Let's consider the technological scheme of obtaining the soil amendment when combining anaerobic digestion and pyrolysis technologies (Fig. 2). After biogas production $97 \%$ of digestate remains. After separation and drying the digestate can be sent for pyrolysis or directly used in the mixing unit to prepare the soil additive. Pyrolysis of AR resulted in the following products: pyrolysis gas (17\%), pyrolysis liquid (45\%) and solid carbonaceous residue ( $38 \%)$. The pyrolysis products composition is dominated by pyrolysis liquid. In the solid charcoal residue, the content of volatile components was $25.08 \%$, and fixed carbon $47.94 \%$. Because the carbon content of the solid charcoal residue is less than $50 \%$, it cannot 
be classified as biochar. Mixing digestate and solid carbonaceous residue provides a new composite soil additive.

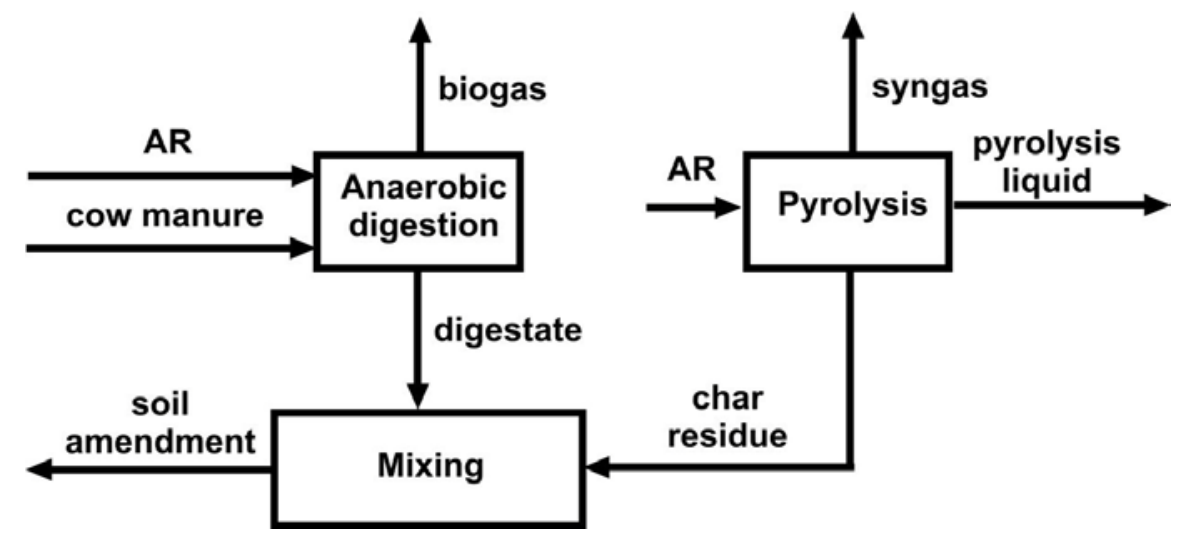

Fig. 2. Scheme of obtaining the soil amendment

The characteristics and elemental composition of the investigated samples are presented in Table 1.

Table 1. Characteristics of the tested samples

\begin{tabular}{|c|c|c|c|}
\hline Characteristics & Digestate & AR & Char residue \\
\hline Moisture, \% per working mass & 7.35 & 7.43 & 7.25 \\
\hline Ash content, \% per working mass & 25.78 & 14.18 & 33.98 \\
\hline Elemental composition per combustible & & & \\
mass, \%: & 35.6 & 38.0 & 46.0 \\
C & 4.4 & 5.1 & 4.5 \\
H & 1.8 & 2.7 & 3.2 \\
N & & & \\
\hline
\end{tabular}

Carbon and ash content in the carbonaceous residue increases with increasing pyrolysis temperature [10]. At the same time, higher temperature contributes to a more intense volatile matter yield and pore formation, which affects the structure of the carbonaceous residue itself. Thus, further research is needed to obtain composite soil amendments from digestate and solid carbonaceous residue to obtain the specified characteristics. To assess the use of such a product it is necessary to take into account not only its quality indicators, but also the type, structure of the soil, methods of application, type of cultivated crops, etc.

The mineral composition of the components of the composite soil amendment is considered (Table 2). Mass proportions of nutrients in the components of the amendment are high and exceed the values recommended by regulatory documents. The samples under study did not contain toxic elements: lead, cadmium, mercury, arsenic, and nickel. It should be noted that the content of zinc and copper exceeds the maximum allowable concentrations recommended by GOST 33380-2015. Thus, it is advisable to add other 
components characterized by "poor" mineral composition, such as peat, which is used to improve the physical and mechanical characteristics of soils.

Table 2. Content of macro- and microelements, $\%$

\begin{tabular}{|c|c|c|c|c|c|}
\hline $\begin{array}{c}\text { Chemical } \\
\text { Element }\end{array}$ & Digestate & $\begin{array}{c}\text { Char } \\
\text { residue }\end{array}$ & $\begin{array}{c}\text { Chemical } \\
\text { Element }\end{array}$ & Digestate & $\begin{array}{c}\text { Char } \\
\text { residue }\end{array}$ \\
\hline $\mathbf{C a}$ & 41.23 & 35.09 & $\mathbf{A l}$ & 1.31 & - \\
\hline $\mathbf{S i}$ & 18.19 & 1.33 & $\mathbf{T i}$ & 0.43 & - \\
\hline $\mathbf{K}$ & 19.30 & 51.85 & $\mathbf{M n}$ & 0.27 & 0.17 \\
\hline $\mathbf{C l}$ & 4.51 & 3.15 & $\mathbf{Z n}$ & 0.14 & 0.07 \\
\hline $\mathbf{P}$ & 4.40 & 2.60 & $\mathbf{S r}$ & 0.10 & 0.07 \\
\hline $\mathbf{M g}$ & 3.66 & 3.56 & $\mathbf{C u}$ & 0.06 & 0.17 \\
\hline $\mathbf{F e}$ & 3.57 & 0.53 & $\mathbf{Z r}$ & 0.04 & - \\
\hline $\mathbf{S}$ & 2.77 & 1.46 & $\mathbf{B r}$ & 0.03 & 0.06 \\
\hline
\end{tabular}

\section{Conclusions}

Weed AR plant can be utilized to obtain useful products. When used in the process of biogas production, the biomass of this plant allows accelerating the processes of methanogenesis. Parts of the plant, stems and inflorescences with seeds that are undesirable to use in biogas plant or remaining in excess can be sent to the pyrolysis unit. Thermochemical recycling of AR produces gas, pyrolysis fluid, and a solid carbonaceous residue. Digestate and solid carbonaceous residue can be used to make composite amendments for soil. Both components of the amendment are characterized by high concentrations of total nitrogen, phosphorus and potassium. The resulting additive has a very high potential as a source of nutrients because it contains a large amount of mineral components.

\section{References}

1. A. Wysocka-Czubaszek, J. Ecol. Eng., 20, 108-117 (2019)

2. M. Koszel, S. Parafiniuk, A. Szparaga, A. Bochniak, S. Kocira, A.Z. Atanasov, S. Kovalyshyn, Agron. 10, 878 (2020)

3. M. Laghari, D.S. Müller-Stöver, M. Puig-Arnavat, T.P. Thomsen, U.B. Henriksen, Waste Biomass Valor. (2021)

4. J. Han, Y. Dong, M. Zhang, Appl. Soil Ecol., 165, 103966 (2021)

5. J. Song, Y. Wang, S. Zhang, Y. Song, S. Xue, L. Liu, X. Lvy, X. Wang, G. Yang, Renew. Sust. Energ. Rev., 144, 110973 (2021)

6. I. Greenberg, M. Kaiser, A. Gunina, P. Ledesma, S. Polifka, K. Wiedner, C.W. Mueller, B. Glaser, B. Ludwig, Sci. Total Environ, 680, 181-189 (2019)

7. J. Zhang, C. li, G. Li, Y. He, J. Yang, J. Zhang, Agric. Ecosyst. Environ., 317, 107453 (2021)

8. B.R. Grigoryan, A.N. Grachev, V.I. Kulagina, L.M. Sungatullina, T.G. Koltsova, S.S. Ryazanov, Bull. Techn. Univ, 19(11), 185-189 (2016)

9. J.V. Karaeva, S.S. Timofeeva, Bull. Ulyanovsk Agric. Acad, 4(48), 6-10 (2019)

10. A. Tomczyk, Z. Sokołowska, P. Boguta, Rev. Environ. Sci. Biotechnol., 19, 191-215 (2020) 